\title{
A 1.7 - 2.5 GHz Active Inductor based Low Power Low Noise Amplifier for Multi Standard Applications
}

\author{
V. Vaithianathan \\ Assistant Professor, \\ SSN College of Engineering, \\ Kalavakkam-603110 \\ Chennai, India
}

\author{
J. Raja \\ Professor\& Head, \\ Anna University of \\ Technology, \\ Tiruchirapalli- 620024 \\ India
}

\author{
R. Srinivasan \\ Professor, \\ SSN College of \\ Engineering, Kalavakkam- \\ 603110 Chennai, India
}

\begin{abstract}
Due to an increasing demand for simultaneous global roaming and all-in-one wireless phones, the interest in the development of the multi-standard transceivers has been increased. In the receiver front end, the performance of Low Noise Amplifier (LNA) decides overall receiver sensitivity and hence its design plays a crucial role. In this paper, an active inductor based tunable two-stage LNA employing current reuse technique is proposed for multistandard applications. The LNA is aimed at supporting CDMA-2000, GSM, WCDMA, WiMAX, Bluetooth and UMTS-TDD in the bandwidth range of $1.7-2.5 \mathrm{GHz}$. The proposed LNA achieved a power gain of greater than 13 $\mathrm{dB}$, noise figure less than $2 \mathrm{~dB}$ and impedance matching less than $-8 \mathrm{~dB}$ for all the standards. The stability factor is maintained above 1, ensuring stable operation of the LNA without oscillations. The LNA consumes very low power of $7.96 \mathrm{~mW}$ at an operating voltage of $1 \mathrm{~V}$. The performance analysis of the proposed active inductor based tunable LNA is carried out using Agilent's ADS simulator employing $90 \mathrm{~nm}$ CMOS technology.
\end{abstract}

\section{General Terms}

RF Circuit Design, Full Custom VLSI Design

\section{Keywords}

Multi Standard, Active Inductors, Tunable LNAs, Cascode Amplifier, Noise Figure

\section{INTRODUCTION}

Starting from the invention of telephone by Alexander Graham Bell to the latest fourth generation cellular wireless applications, everything has been driven by curiosity, especially in the pursuit of quality of life. In today's fast paced world, wireless communications are becoming increasingly popular owing to the mobility, portability and unlimited access to information it provides. The evolution of wireless technologies has been incredibly rapid and the future of this growth is endless. With the advent of $3 \mathrm{G}$ and $4 \mathrm{G}$ cellular systems, it has become quite essential to integrate many standards into a single wireless terminal [1]. According to an increasing demand for simultaneous global roaming and all-in-one wireless phones, the interest in the development of the multistandard transceivers has been increased.

\subsection{Multi Standard Receiver Front End}

A Multi Standard Receiver can be implemented either by integrating different modules of individual standards on a single hardware chip or by using Software Defined Radio (SDR) [2]. A typical multi-standard receiver front-end comprises of a tunable LNA, a filter and a down conversion mixer as shown in Fig 1. It poses a unique challenge in the receiver design as the operating points of different components in the receiver must be set in such a way that it can provide an optimal performance for all the required standards.

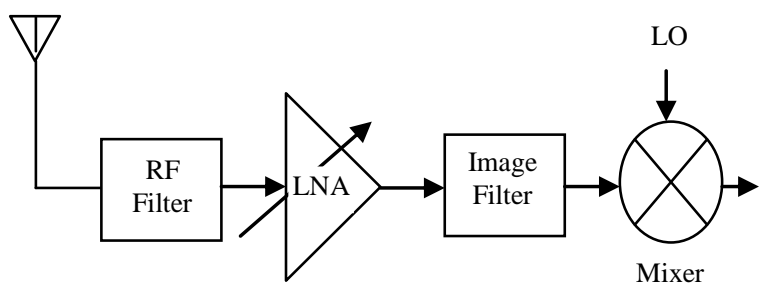

Fig 1: A Multi Standard Receiver Front End

The most popular standards that are currently in use are Worldwide Interoperability for Microwave Access (WiMAX), Code Division Multiple Access 2000 (CDMA2000), Global System for Mobile Communications (GSM), Wideband CDMA (WCDMA), Universal Mobile Telecommunication Systems Time Division Duplex (UMTS TDD) and Bluetooth (BT) [3] and [4]. The operating frequencies of the different standards are given in Table 1.

Table 1. Operating frequencies of the chosen standards

\begin{tabular}{|c|c|}
\hline Standard & Frequency $(\mathrm{GHz})$ \\
\hline CDMA2000 & 1.7 \\
\hline GSM & 1.9 \\
\hline WCDMA & 2.1 \\
\hline WiMAX & 2.3 \\
\hline Bluetooth/WLAN & 2.4 \\
\hline UMTS TDD & 2.5 \\
\hline
\end{tabular}




\subsection{Reconfigurable LNAs}

The reconfigurable LNAs form the core of a multi standard receiver and it decides the overall efficiency of the system. The simplest way to obtain tunability is the use of switched capacitors [5] and switched inductors [6] but they both suffer from very high noise figure. The tunability can also be achieved by varying the resonant frequency of the ladder network using MOS varactors [7], [8]. The use of varactors reduces the circuit stability and its fabrication is also difficult. A con-current dual band LNA is used in [9] and [10] but it requires a precise characterization of the inductors and the capacitors used in the LC ladder which is extremely tedious.

\subsection{Active Inductors}

The active inductors use only MOS transistors connected in such a way that it can perform the function of conventional spiral inductors. They facilitate easy tuning of inductance with high quality factor and they also occupy less area when compared to spiral inductors [11]. The most commonly used active inductor structure is Gyrator C active inductor the schematic of which is given in Fig 2 . The use of active inductors in multi standard receivers is proposed in [12] which uses digital band selector for
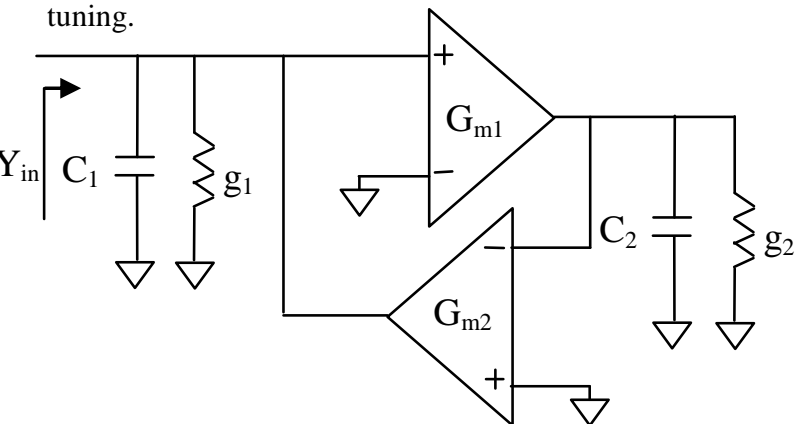

Fig 2: Gyrator C Active Inductor
In this paper, we proposed a low voltage high dynamic range CMOS active inductor based tunable LNA. The rest of the paper is organized as follows. Section 2 presents the circuit structure and operation of the proposed active inductor based tunable LNA for multi-standard applications. The simulation results and the performance analysis of the proposed active inductor based tunable LNA are presented in Section 3. The conclusions are given in Section 4.

\section{PROPOSED LNA}

The proposed LNA circuit comprises of two main stages, a cascade stage, with two common gate transistors $\left(\mathrm{M}_{1}\right.$ and $\mathrm{M}_{2}$ ) stacked one on top of the other and a cascode stage made up of a common source $\left(\mathrm{M}_{3}\right)$ followed by a common gate $\left(\mathrm{M}_{4}\right)$ transistor as shown in Fig 3. Both stages employ a current reuse technique for power reduction and gain enhancement. The equivalent circuits are given in Fig 4, Fig 5 and Fig 6. The first stage common gate transistor $\left(\mathrm{M}_{1}\right)$, having low input impedance is used to obtain a perfect $50 \Omega$ termination. By a proper choice of the device dimensions and by using a suitable combination of inductors and capacitors the input matching can be maintained below $-10 \mathrm{~dB}$. The input impedance of the proposed LNA is derived as given in equation (1)

$$
Z_{i n} \approx \frac{1}{s C_{1}}+\frac{s L_{1}}{1+s^{2} L_{1} C_{g s 1}}
$$

The parasitic capacitance present in the equation will make the input matching get worse at a high frequency. So best input matching is obtained at the resonant frequency which is given by equation (2)

$$
\omega_{i n} \approx \frac{1}{\sqrt{L_{1}\left(C_{g s 1}+C_{1}\right)}}
$$

The cascade stage constructed with the transistors $\mathrm{M}_{1}$ and $M_{2}$ is used to achieve sufficient gain with higher bandwidth. It also reduces the effect of the parasitic capacitance at the drain terminals of the transistors. The inductance at the drain of $M_{1}\left(L_{3}\right)$ provides an advantage that it offers no extra dc voltage drop. The cascode arrangement reduces the Miller feedback capacitance [13], thereby isolating the input from the output return signals. This stage further enhances the amplification of the LNA The gain equations for the proposed LNA are given by the following equations.

$$
A_{V 1} \approx g_{m 1} Z_{1}
$$

where

$$
\begin{aligned}
& Z_{1} \approx\left(s L_{3}+\frac{1}{s C_{2}}\right) \|\left(s L_{3}+\frac{1}{s C_{g s 2}}\right) \\
& A_{V 2} \approx g_{m 2} Z_{2}
\end{aligned}
$$

where

$$
\begin{aligned}
& Z_{2} \approx s L_{4} \| \frac{1}{s C_{i n 3}} \\
& C_{i n 3} \approx C_{g s 3}+\left(1+A_{V 3}\right) C_{g d 3} \\
& A_{V 3} \approx g_{m 3} Z_{3} \\
& Z_{3} \approx\left(s L_{6}+\frac{1}{s C_{3}}\right) \|\left(s L_{5}+\frac{1}{s C_{g s 4}}\right) \\
& A_{V 4} \approx g_{m 4} Z_{4} \\
& Z_{4} \approx s L_{7} \| \frac{1}{s C_{i n 5}} \\
& C_{i n 3} \approx C_{g s 5}+C_{g d 5} \\
& A_{V 5} \approx \frac{g_{m 5} r_{o 5}}{1+g_{m 5} r_{o 5}} \\
& A_{V} \approx A_{V 1} \times A_{V 2} \times A_{V 3} \times A_{V 4} \times A_{V 5}
\end{aligned}
$$

The circuit incorporates a current reuse technique [14] to effectively distribute the operating current and prevent it from sinking to the ground. This leads to improved power performance and overall gain flatness. 


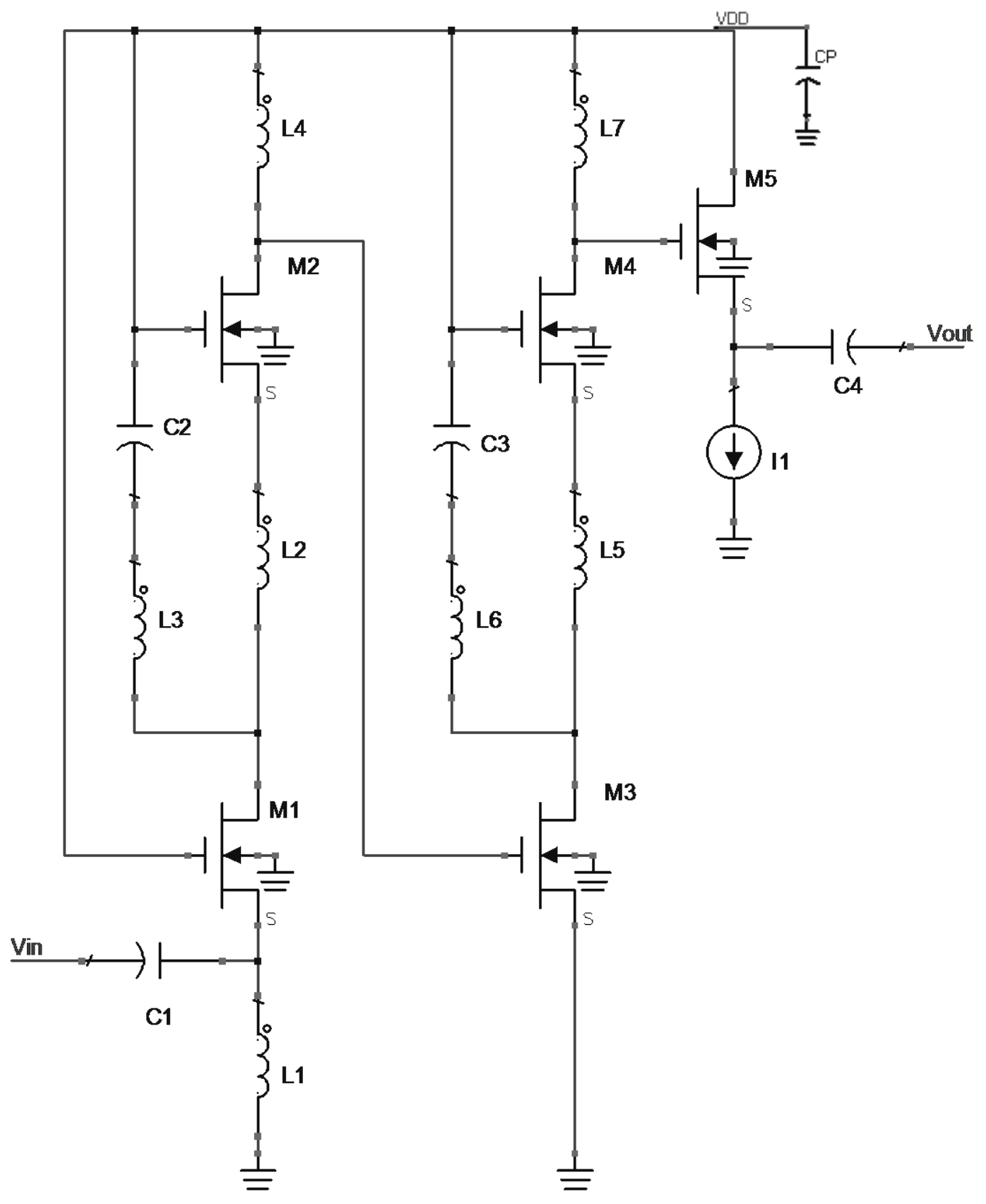

Fig 3: Proposed LNA

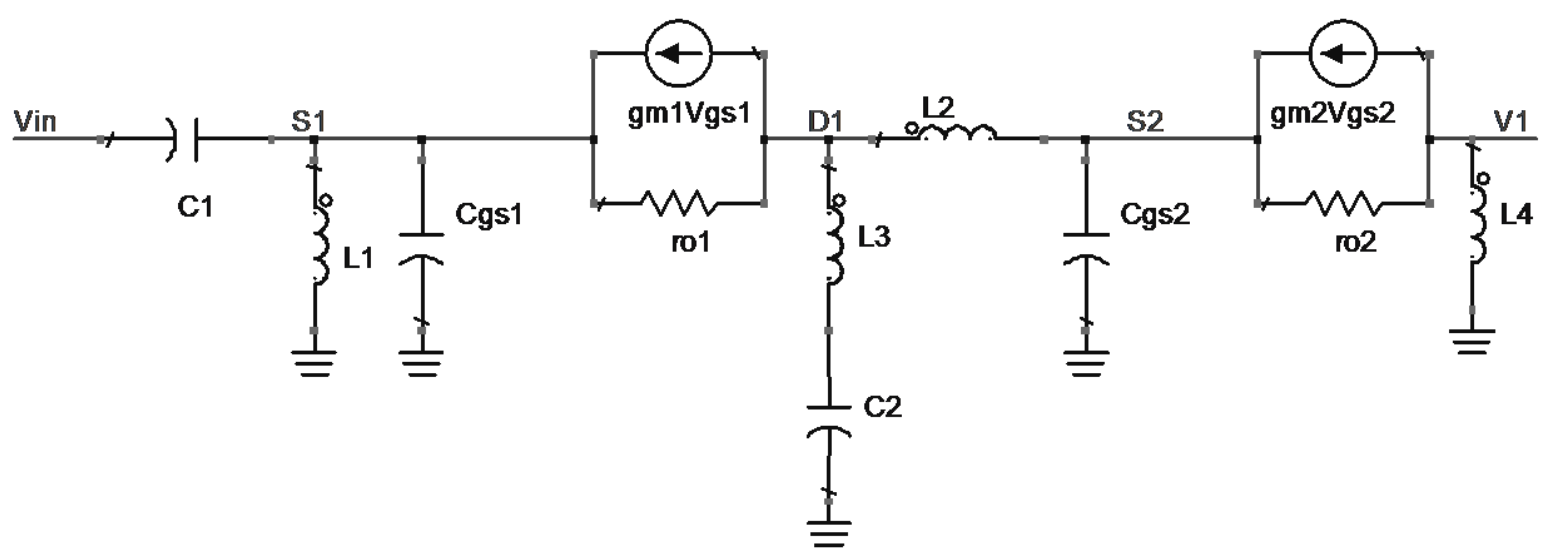

Fig 4: First Stage Equivalent Circuit 


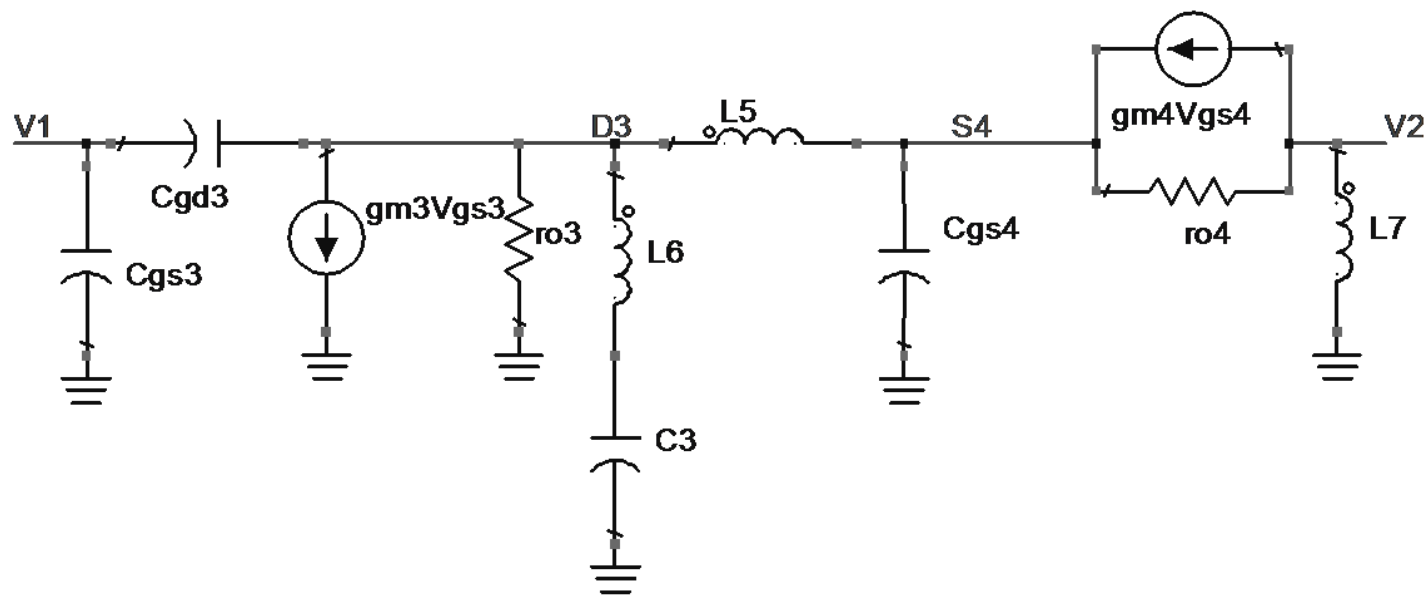

Fig 5: Second Stage Equivalent Circuit

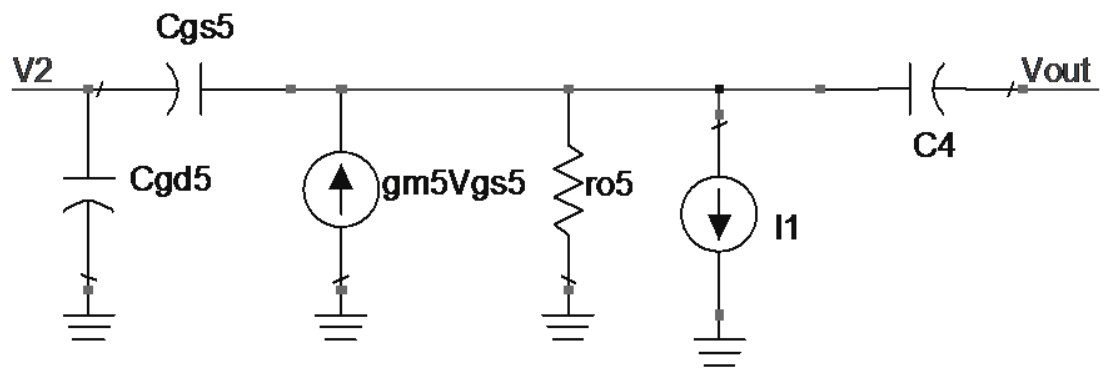

Fig 6: Buffer Equivalent Circuit

The current reuse configuration involves the use of cascode transistors along with a drain load inductance $\left(\mathrm{L}_{3}\right)$, and the loop inductance $\left(\mathrm{L}_{2}\right)$ and capacitance $\left(\mathrm{C}_{1}\right)$. A portion of the dc supply voltage is dropped across capacitor $\mathrm{C}_{1}$. By principle this charge is stored by $\mathrm{C}_{1}$, which can be used to bias the upper common gate transistor. Thus this transistor does not consume the entire voltage provided by the supply, leading to lesser power consumption.

In general, the load inductance at the drain has a value greater than the loop inductance. At the high operating frequencies the inductance $\mathrm{L}_{3}$ provides a high impedance path. Thus the signal current flows through the lower impedance path containing $L_{2}$ and $C_{1}$, enabling the reuse of this current. As a result the input signal can be amplified twice, giving rise to better gain than the normal structure. Using this configuration we obtain a high gain with low power consumption. It is important to understand that a large loop capacitance is preferred in the design for a better signal coupling. With $\mathrm{M}_{1}$ and $\mathrm{M}_{2}$ sharing the same bias current, the total power consumption of the currentreused amplifier is minimized. The same principle can be used to describe the reuse of current in the second stage. The design considerations of the current-reused LNA are similar to those of cascaded amplifier. The common drain amplifier offers low output impedance, thus making it a suitable choice to be placed at the output end for perfect matching. The output impedance of the LNA is derived as

$$
Z_{\text {out }} \approx r_{o 5}
$$

A constant current source is used at the output of the buffer in order to obtain linear input-output transfer characteristics [15].
Table 2. Values of the variable inductors for all six standards

\begin{tabular}{|c|c|c|c|c|}
\hline Standard & $\begin{array}{c}\text { L3 } \\
(\mathbf{n H})\end{array}$ & $\begin{array}{c}\text { L4 } \\
(\mathbf{n H})\end{array}$ & $\begin{array}{c}\text { L6 } \\
(\mathbf{n H})\end{array}$ & $\begin{array}{c}\text { L7 } \\
(\mathbf{n H})\end{array}$ \\
\hline $\begin{array}{c}\text { CDMA } \\
2000\end{array}$ & $\mathbf{9 . 0 8}$ & $\mathbf{6 . 9}$ & $\mathbf{8 . 0 5}$ & $\mathbf{6 . 1 4}$ \\
\hline GSM & $\mathbf{8 . 4 1}$ & $\mathbf{6}$ & $\mathbf{7 . 8 6}$ & $\mathbf{6 . 5 3}$ \\
\hline WCDMA & $\mathbf{7 . 8 5}$ & $\mathbf{6 . 1 5}$ & $\mathbf{7 . 5}$ & $\mathbf{7 . 1 2}$ \\
\hline WiMAX & $\mathbf{7 . 3 3}$ & $\mathbf{7 . 1}$ & $\mathbf{6 . 3 3}$ & $\mathbf{7 . 8 4}$ \\
\hline BT & $\mathbf{6 . 9 6}$ & $\mathbf{7 . 6}$ & $\mathbf{6 . 1 4}$ & $\mathbf{8 . 3 4}$ \\
\hline UMTS TDD & $\mathbf{6 . 2 4}$ & $\mathbf{5 . 9 6}$ & $\mathbf{6 . 0 8}$ & $\mathbf{8 . 5 2}$ \\
\hline
\end{tabular}

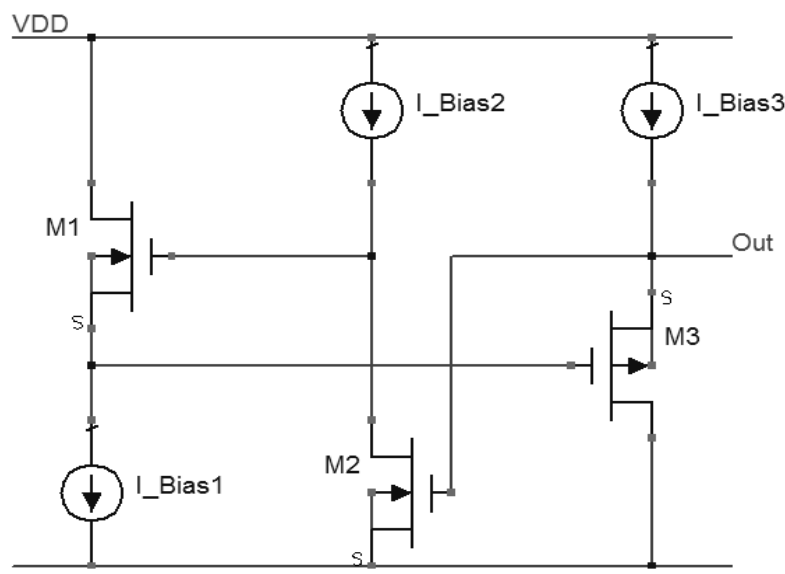

Fig 7: Low Voltage CMOS Gyrator C Active Inductor

In our proposed LNA the inductors $\mathrm{L}_{3}, \mathrm{~L}_{4}, \mathrm{~L}_{6}$ and $\mathrm{L}_{7}$ are made tunable in order to make a single LNA compatible for multi standard applications. A low voltage CMOS Gyrator $\mathrm{C}$ active inductor as proposed by Ngow and 
Thanachayanont in [16] is employed in our circuit to achieve the desired tunability. The schematic of this active inductor is given in Fig 7. The current source I_Bias2 is varied in order to obtain different values of inductances suitable for various standards. The circuit offers easy biasing and it also ensures a better stability [17].

\section{SIMULATION RESULTS}

The simulations are done in Agilent's Advanced Design System (ADS) using CMOS $90 \mathrm{~nm}$ process along with the macro model generated for tunable capacitor and inductor.
The simulation results are presented in Fig 8 to 14 . The parameters such as Quality Factor(Q), Input Matching $\left(S_{11}\right)$, Reverse Isolation $\left(S_{12}\right)$, Power Gain $\left(S_{21}\right)$, Noise Figure (NF), Output Matching $\left(\mathrm{S}_{22}\right)$ are verified for each of the six standards.

\subsection{Quality Factor $(\mathbf{Q})$}

The Fig 8 shows the obtained quality factor for the proposed active inductor over frequency range of 1.7 to 2.6 $\mathrm{GHz}$. Its value ranges from 51.6 to 53.5 which is acceptable for our applications.

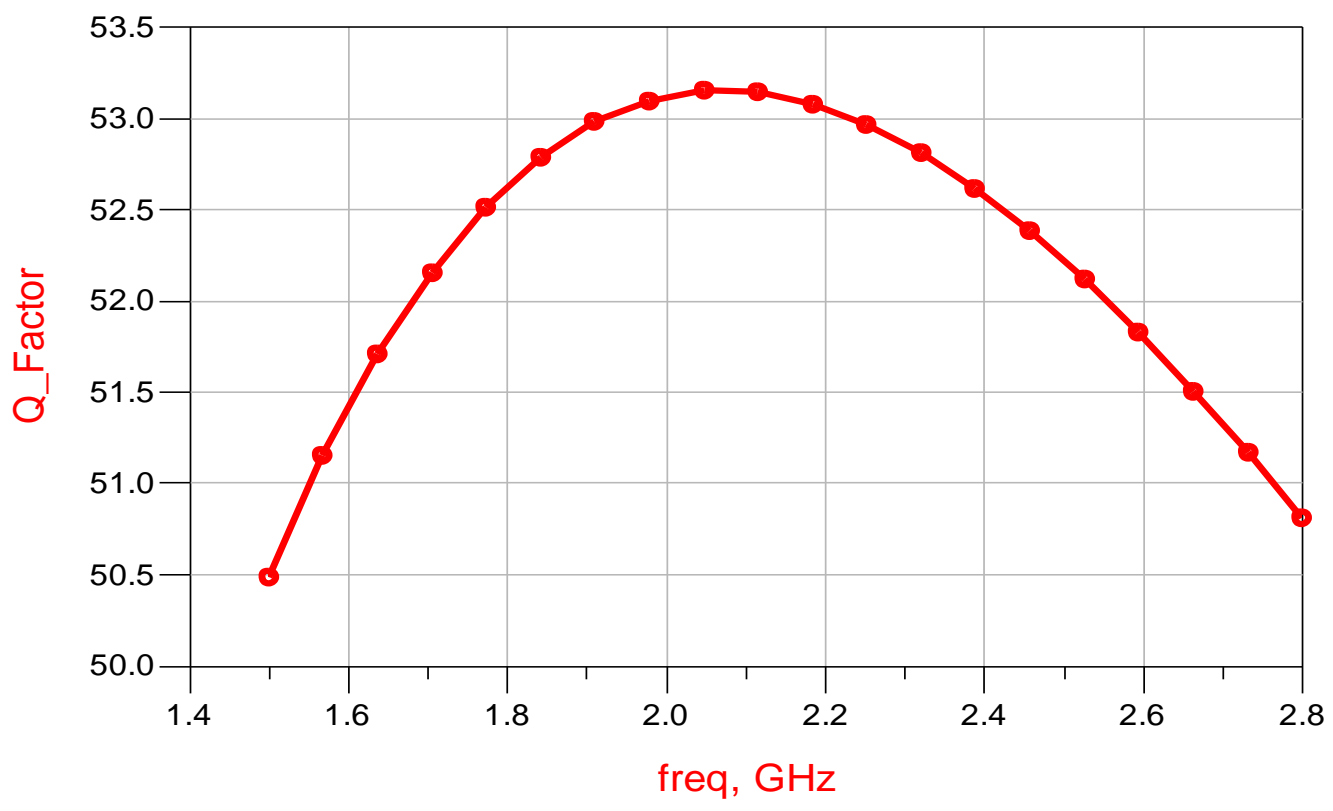

Fig 8: Quality Factor $(\mathbf{Q})$

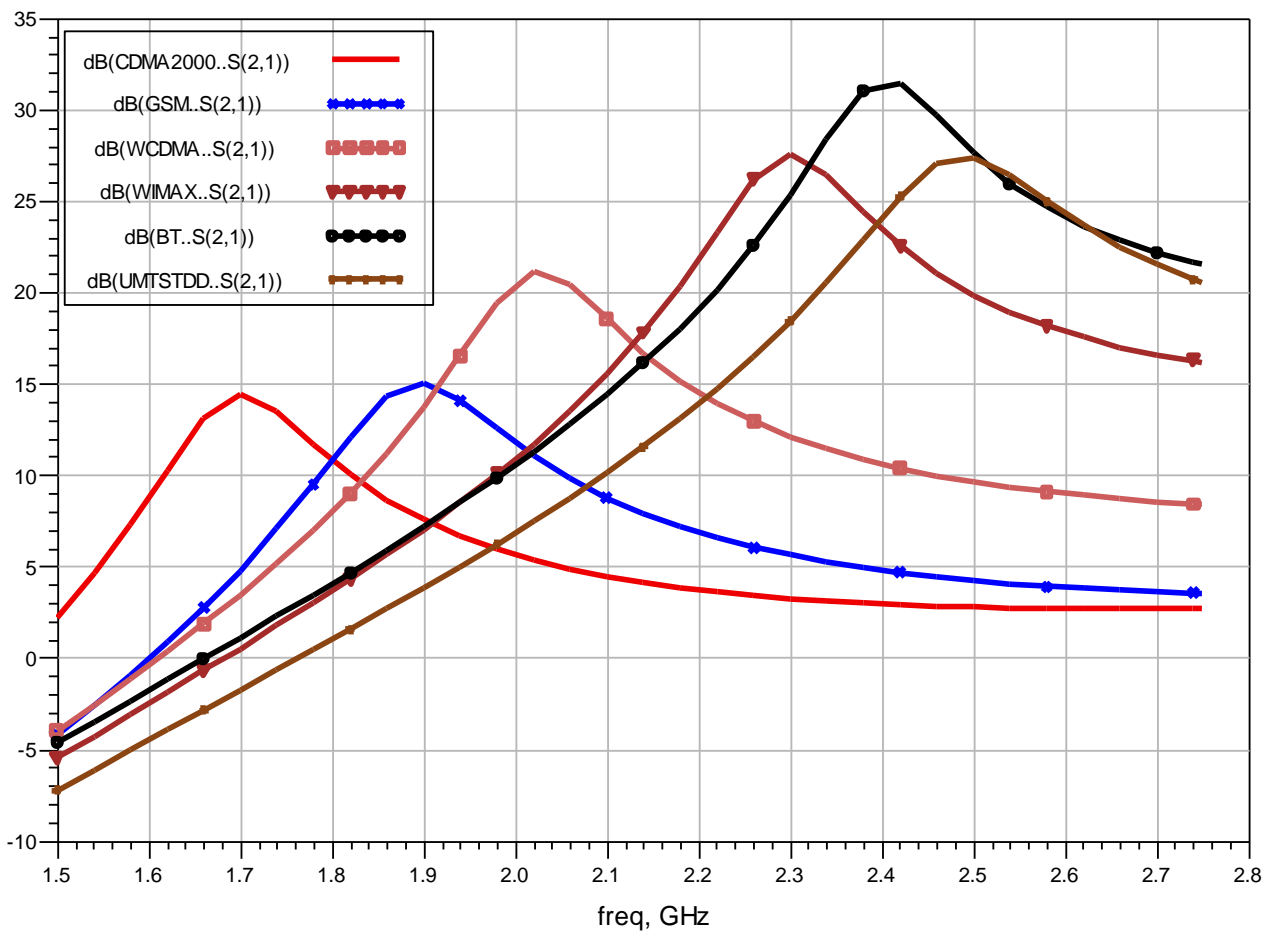

Fig 9: Power Gain $\left(\mathbf{S}_{21}\right)$. 


\subsection{Power Gain $\left(\mathbf{S}_{21}\right)$}

Fig 9 shows the power gain which is above $13 \mathrm{~dB}$ at the operating frequencies for all the standards. A maximum gain of $33 \mathrm{~dB}$ is obtained for $\mathrm{BT}$ at $2.4 \mathrm{GHz}$

\subsection{Noise Figure (NF)}

Fig 10 plots the noise figure of the LNA which is observed to below $2 \mathrm{~dB}$ for all the required frequencies. A minimum noise figure of $1.3 \mathrm{~dB}$ was obtained at a frequency of $1.7 \mathrm{GHz}$ which corresponds to CDMA 2000.

\subsection{Input Matching $\left(\mathrm{S}_{11}\right)$}

The input matching is kept well below $-8 \mathrm{~dB}$ for all the standards as shown in Fig 11. The best matching is obtained for WiMAX where $\mathrm{S}_{11}$ is $-15 \mathrm{~dB}$ at $2.3 \mathrm{GHz}$.

\subsection{Output Matching $\left(\mathbf{S}_{22}\right)$}

Fig 12 shows output matching characteristics for the proposed LNA. It is evident that for all the desired frequencies it is kept well below $-10 \mathrm{~dB}$ so that there are minimal reflections at the load resulting in efficient power transfer.

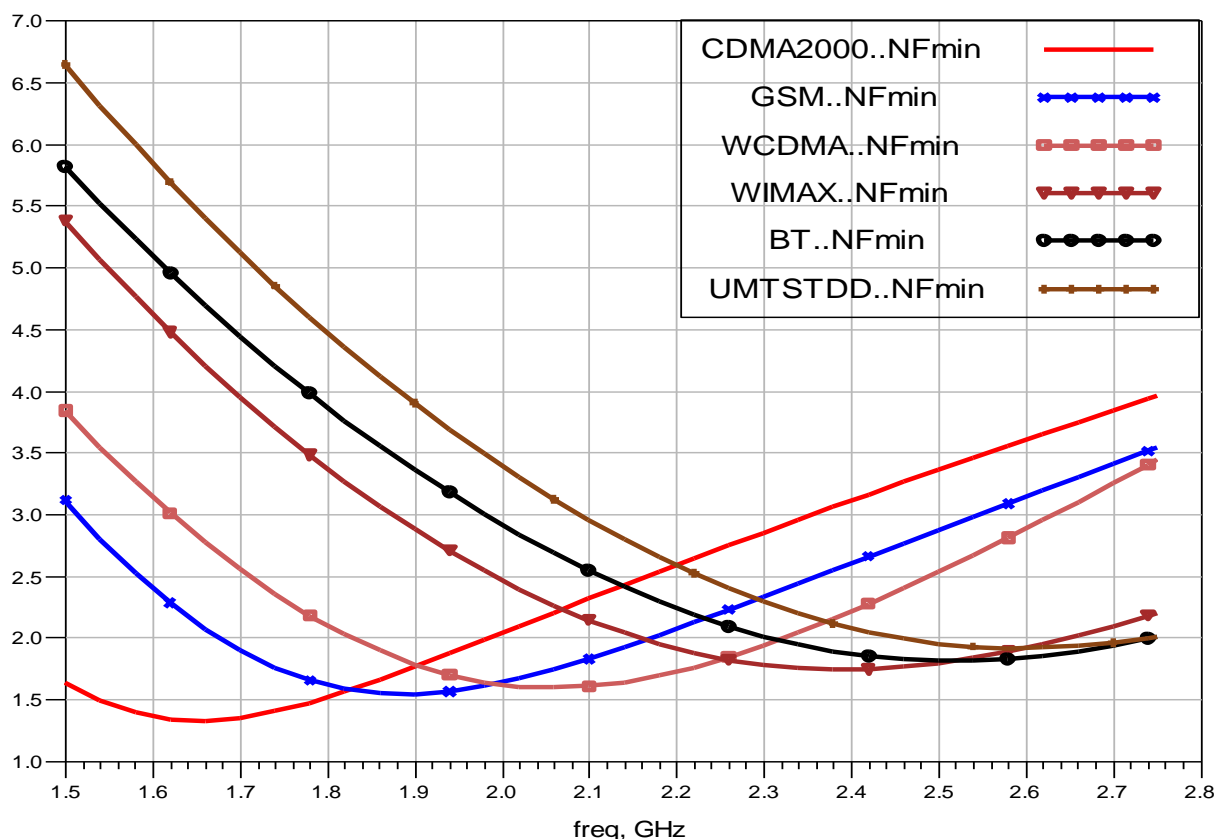

Fig 10: Noise Factor (NFmin)

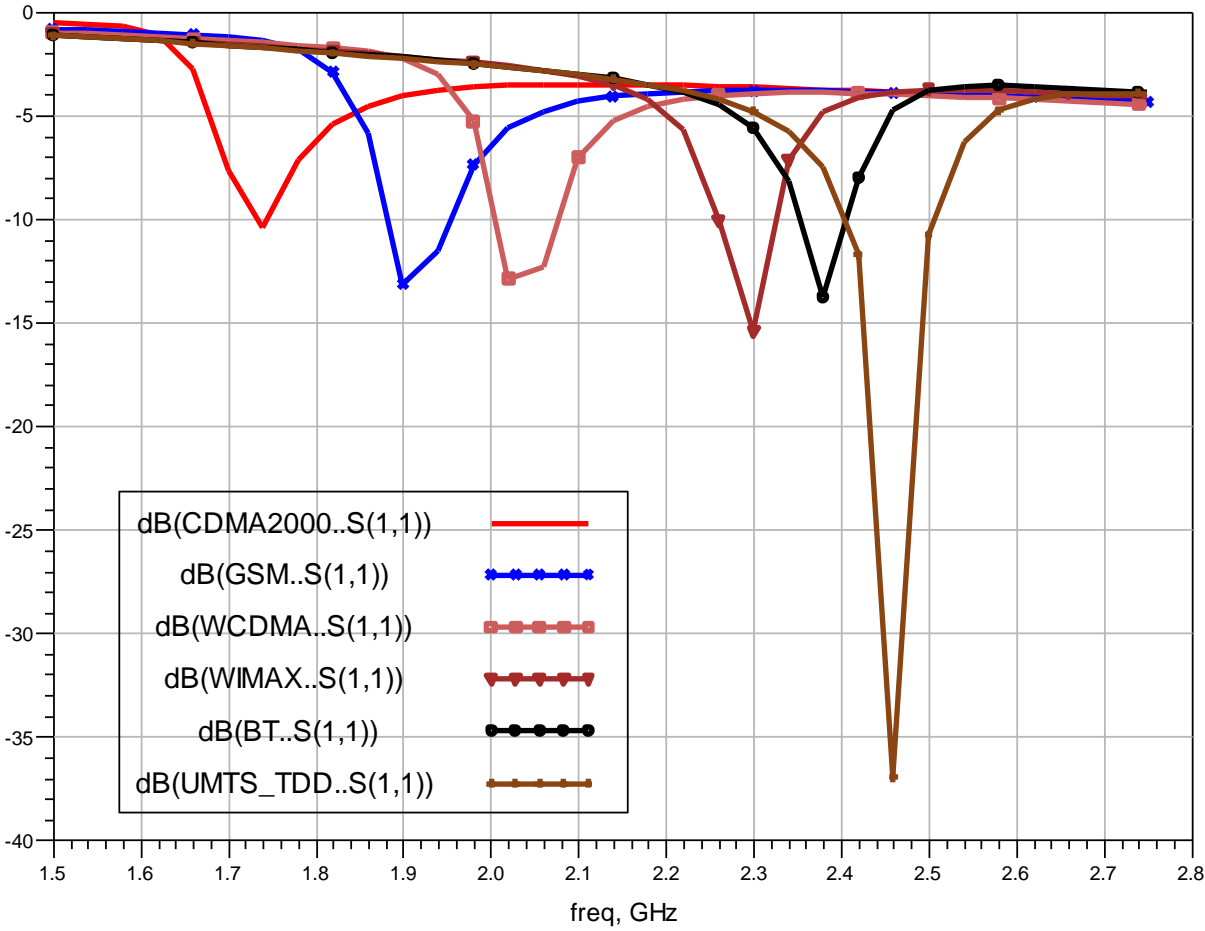

Fig 11: Input Matching $\left(S_{11}\right)$ 


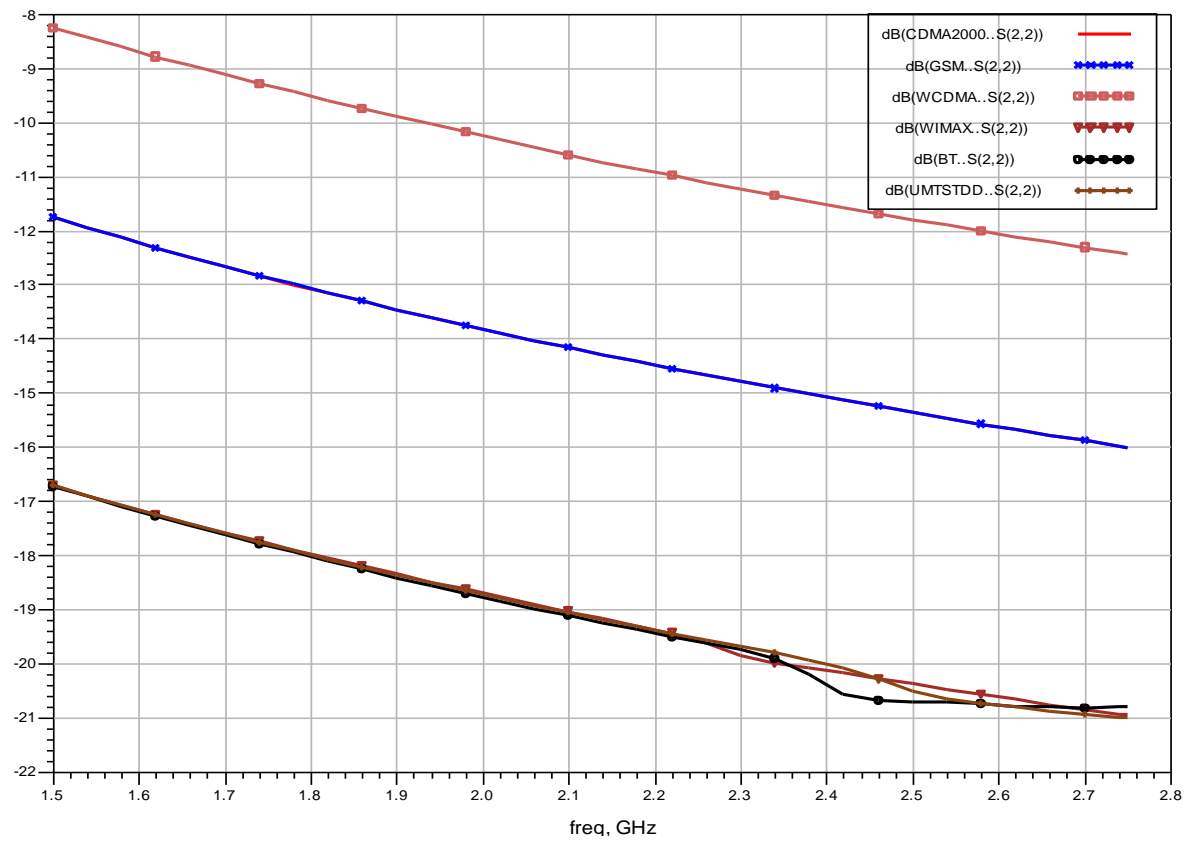

Fig 12: Output Matching $\left(\mathbf{S}_{22}\right)$

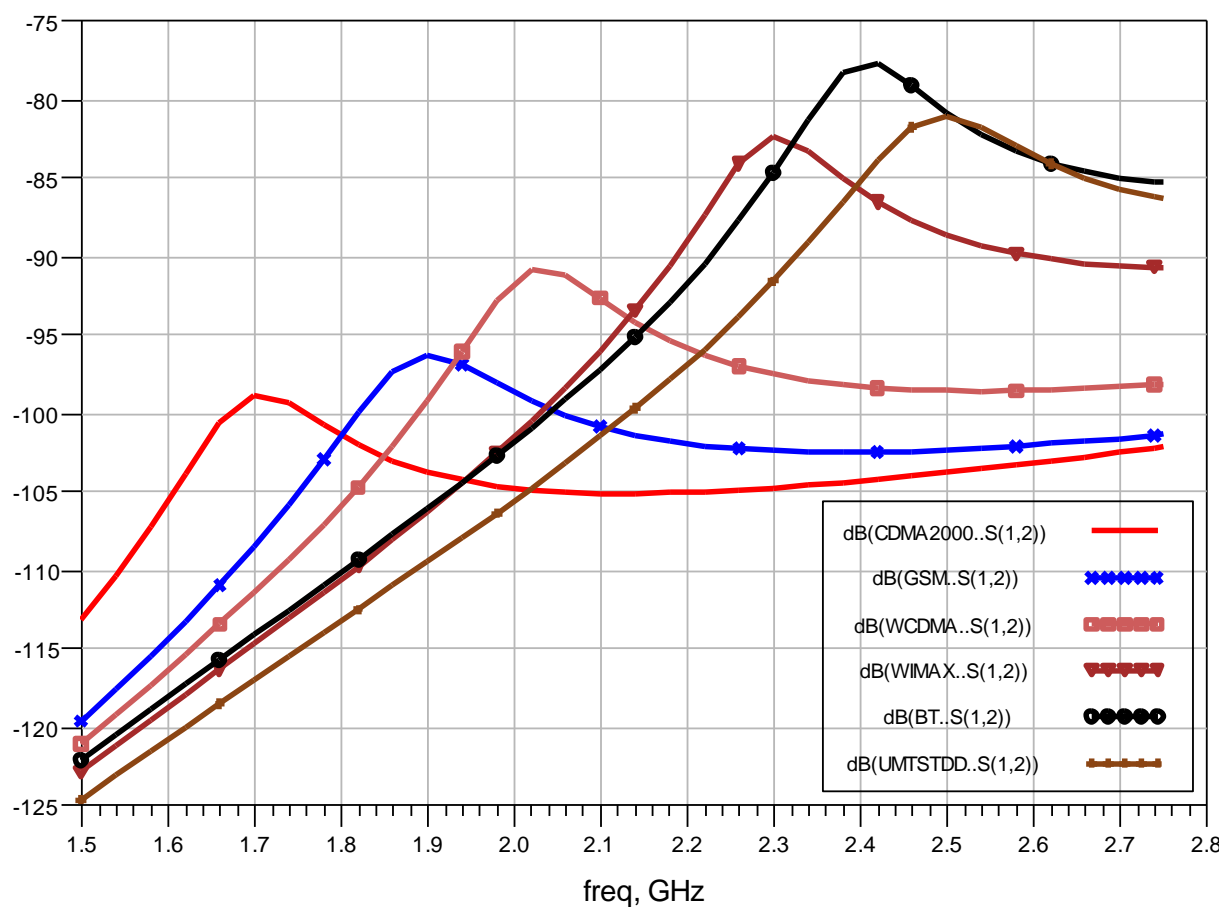

Fig 13: Reverse Isolation $\left(S_{12}\right)$

\subsection{Reverse Isolation $\left(S_{12}\right)$}

The reverse isolation characteristic is presented in Fig 13, with a minimum value of $-99 \mathrm{~dB}$ corresponding to the CDMA-2000. The value is kept well below $-77 \mathrm{~dB}$ throughout the entire frequency range, thereby offering better stability to the design.

\subsection{Stability Factor (K)}

The Rollett stability factor, ' $\mathrm{K}$ ' is calculated for all the standards by using the equation (16). It is observed that the value of ' $\mathrm{K}$ ' is above unity thereby ensuring that the circuit is unconditionally stable without oscillations [18].

$$
K=\frac{1+\left|S_{11} S_{22}-S_{12} S_{21}\right|^{2}-\left|S_{11}\right|^{2}-\left|S_{22}\right|^{2}}{2\left|S_{12} S_{21}\right|}
$$

The Table 3 presents the performance summary of the proposed LNA for all six standards and the Table 4 presents a comparison of simulation results of the proposed LNA with recently reported LNAs. 


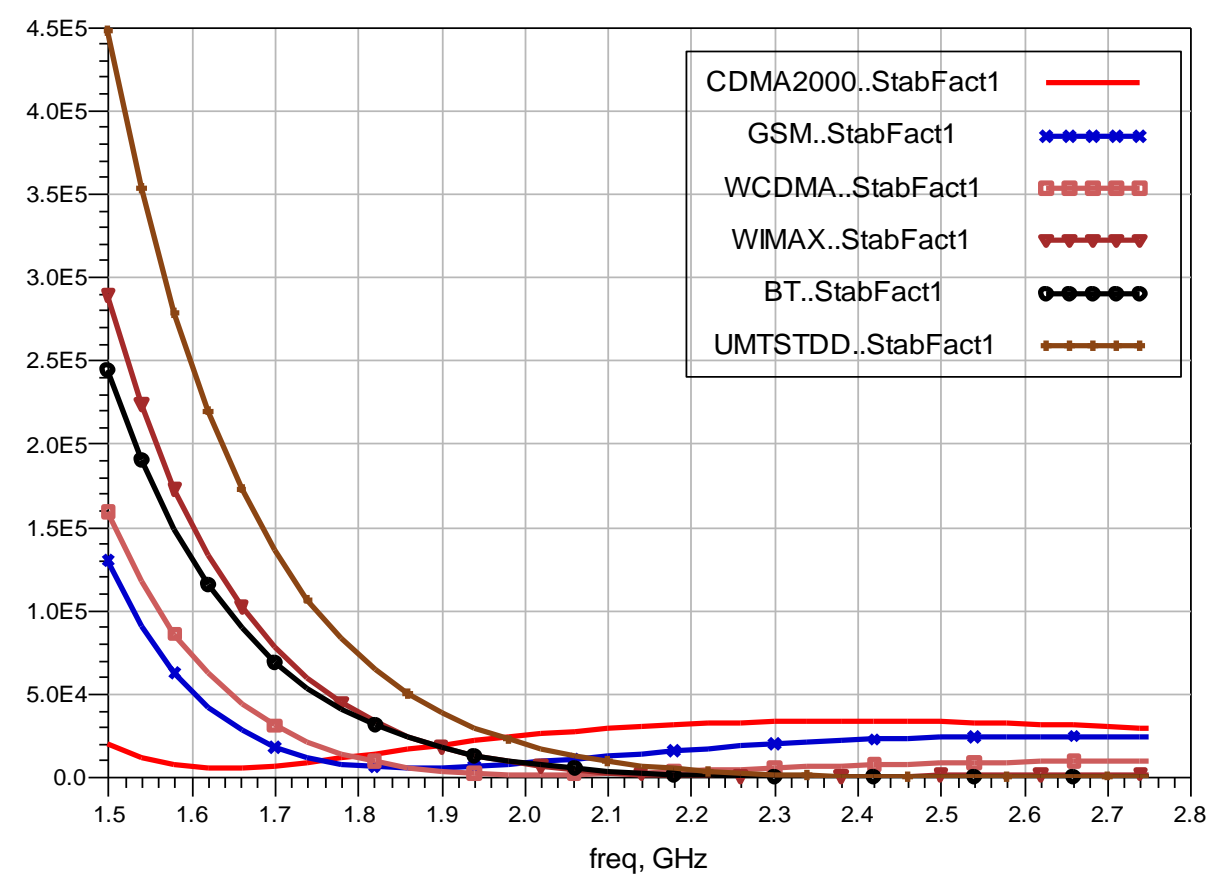

Fig 14: Stability Factor

Table 3: Performance summary of the proposed LNA for all six standards

\begin{tabular}{|c|c|c|c|c|c|c|}
\hline Standard & $\begin{array}{c}\text { Power Gain } \\
\left(\mathrm{S}_{21}\right) \mathrm{dB}\end{array}$ & $\begin{array}{c}\text { Noise Figure } \\
(\mathrm{NF}) \mathrm{dB}\end{array}$ & $\begin{array}{c}\text { Input Matching } \\
\left(\mathrm{S}_{11}\right) \mathrm{dB}\end{array}$ & $\begin{array}{c}\text { Output Matching } \\
\left(\mathrm{S}_{22}\right) \mathrm{dB}\end{array}$ & $\begin{array}{c}\text { Reverse Isolation } \\
\left(\mathrm{S}_{12}\right) \mathrm{dB}\end{array}$ & $\begin{array}{c}\text { Power } \\
(\mathrm{mW})\end{array}$ \\
\hline CDMA2000 & 14 & 1.3 & -8.5 & -12.6 & -99 & 7.408 \\
\hline GSM & 15 & 1.5 & -13.5 & -13.5 & -97 & 7.408 \\
\hline WCDMA & 19 & 1.55 & -8 & -10.7 & -92.5 & 7.86 \\
\hline WiMAX & 27.5 & 1.75 & -15 & -19.6 & -82.5 & 7.968 \\
\hline BT & 33 & 1.8 & -10 & -20.4 & -78 & 7.968 \\
\hline UMTS-TDD & 27.5 & 1.9 & -11 & -20.6 & -81 & 7.968 \\
\hline
\end{tabular}

Table 4: Comparison of simulation results of the proposed LNA with recently reported LNAs

\begin{tabular}{|c|c|c|c|c|}
\hline References & Standard & Power Gain $\left(\mathrm{S}_{21}\right) \mathrm{dB}$ & Noise Figure(NF) dB & Power $(\mathrm{mW})$ \\
\hline \multirow{4}{*}[8]{} & GSM & 24.7 & 1.61 & 53.3 \\
\cline { 2 - 5 } & WCDMA & 20.6 & 1.73 & 28.5 \\
\cline { 2 - 5 } & BT & 16.2 & 1.77 & 25.3 \\
\hline \multirow{5}{*}[9]{} & WLAN & 22.3 & 1.64 & 30.5 \\
\cline { 2 - 5 } & GSM $(0.9 \mathrm{GHz})$ & 18 & 4.6 & 32.4 \\
\cline { 2 - 5 } & BT & 24 & 4.4 & 32.4 \\
\hline \multirow{5}{*}[10]{} & WLAN & 24 & 4.4 & 12 \\
\cline { 2 - 5 } & GSM $(0.9 \mathrm{GHz})$ & 16.8 & 1.98 & 12 \\
\hline \multirow{5}{*}{ This Paper } & BT & 31 & 1.92 & $\mathbf{7 . 4 0 8}$ \\
\cline { 2 - 5 } & CDMA2000 & $\mathbf{1 4}$ & $\mathbf{1 . 3}$ & $\mathbf{7 . 4 0 8}$ \\
\cline { 2 - 5 } & GSM & $\mathbf{1 5}$ & $\mathbf{1 . 5}$ & $\mathbf{7 . 8 6}$ \\
\cline { 2 - 5 } & WCDMA & $\mathbf{1 9}$ & $\mathbf{1 . 5 5}$ & $\mathbf{7 . 9 6 8}$ \\
\cline { 2 - 5 } & WiMAX & $\mathbf{2 7 . 5}$ & $\mathbf{1 . 7 5}$ & $\mathbf{7 . 9 6 8}$ \\
\hline
\end{tabular}




\section{CONCLUSION}

In this paper, a multi satandard LNA with current reuse technique for power reduction and gain enhancement is presented. An active inductor is used to tune the proposed LNA so that it can be used for various standards such as WiMAX, CDMA2000, GSM, WCDMA, UMTS TDD, BT. The proposed LNA is designed using $90 \mathrm{~nm}$ CMOS technology and its performance is analyzed by performing simulation using Agilent ADS simulator. The achieved power gain is greater than $13 \mathrm{~dB}$ while reaching its maximum value at the center frequency corresponding to each standard. The achieved noise figure is well less than $2.68 \mathrm{~dB}$ for the desired standards. The input and output matching are well below $-12 \mathrm{~dB}$ and $-14 \mathrm{~dB}$ respectively. The presented LNA claims lowest noise figure while achieving a high power gain with low power consumption. The proposed circuit also has less design complexity. The tunability is attained by the active inductor which leads into lesser area.

\section{ACKNOWLEDGEMENT}

We are grateful to the experts who have contributed towards development of our work. We acknowledge R. Kavya, N. Anuradha and A. Naveen Bharathwaj, for all their help during the design phase.

\section{REFERENCES}

[1] Wenjun Sheng and Edgar Sanchez - Sinencio, "Next Generation Wideband Multi-Standard Digital Receiver Design", Proceedings of $43^{\text {rd }}$ Midwest Symposium on Circuits and Systems, pp $424-427$, $8^{\text {th }}-11^{\text {th }}$ August 2000 .

[2] Ralf E. Schuh, Peter Eneroth and Peter Karlsson, "Multi-Standard Mobile Terminals", Proceedings of IST Mobile \& Wireless Telecom. Summit, pp 174 $178,16^{\text {th }}-19^{\text {th }}$ June 2002.

[3] Andreas F. Molisch, "Wireless Communications", Second Edition, Wiley, Chapter 24 - 26, 2011.

[4] Dharma Prakash Agrawal and Qing-An Zeng, "Introduction to Wireless and Mobile Systems", Third Edition, Cengage Learning, Chapter 11 \& 15, 2011.

[5] V. Vidojkovic, J. van der Tang, E. Hanssen, A. Leeuwenburgh, and A.van Roermund, "Fully Integrated DECT/Bluetooth Multi Band LNA in $0.18 \mu \mathrm{m}$ CMOS", Proceedings of IEEE International Symposium on Circuits and Systems, Vol. 1, pp. 565 $-568,23^{\text {rd }}-26^{\text {th }}$ May 2004

[6] Z. Li, R. Quintal and K. K. O, "A Dual Band CMOS Front End with Two Gain Modes for Wireless LAN Applications," IEEE Journal of Solid-State Circuits, Vol. 39, No. 11, pp 2069 - 2073, Nov 2004.

[7] Chong-Ru Wu and Liang-Hung Lu, "A 2.9-3.5-GHz Tunable Low-Noise Amplifier", $6^{\text {th }}$ Topical Meeting on Silicon Monolithic Integrated Circuits in RF Systems, pp $206-109,18^{\text {th }}-20^{\text {th }}$ January 2006.

[8] E.C. Becerra-Alvarez, F. Sandoval-Ibarra, and J.M. de la Rosa, "Design of a 1-V 90-nm CMOS Adaptive LNA for Multistandard Wireless Receivers", Revista Mexicana De Física, Vol.54, No.4, pp 322 - 328, 2008.

[9] Chyuen-Wei Ang, Yuanjin Zheng and Chun-Huat Heng, "A Multi-Band CMOS Low Noise Amplifier for Multi-standard Wireless Receivers", Proceedings of IEEE International Symposium on Circuits and Systems, pp $2802-2805,25^{\text {th }}$ June 2007.

[10] Sambit Datta, Kunal Datta, Ashudeb Dutta and Tarun Kanti Bhattacharyya, "A Concurrent Low-Area Dual Band $0.9-2.4 \mathrm{GHz}$ LNA in $0.13 \mu \mathrm{m}$ RF CMOS Technology for Multi-Band Wireless Receiver", Proceedings of IEEE Asia Pacific Conference on Circuits and Systems (APCCAS), pp $280-283,6^{\text {th }}-$ $9^{\text {th }}$ Dec. 2010

[11] Qiang-Tao Lai and Jun-Fa Mao, "A New Floating Active Inductor Using Resistive Feedback Technique", Proceedings of Microwave Symposium Digest (MTT), pp. 1748 - 1751, 2010.

[12] Jenn-Tzer Yang, Yuan-Hao Lee, Yi-Yuan Huang, YuMin $\mathrm{Mu}$, and Yen-Ching Ho, "A 0.18um CMOS Using High-Q Active Inductors for Multi-band Low Noise Amplifier", Proceedings IEEE Conference on Electron Devices and Solid-State Circuits (EDSSC), pp 1001 - 1004, 2007.

[13] Randall L. Geiger, Phillip E. Allen and Noel R. Strader, "VLSI Design Techniques for Analog and Digital Circuits", McGraw Hill Publications, Chapter 6, 1990.

[14] Muhammad Khurram and S. M. Rezaul Hasan, "A 3 $5 \mathrm{GHz}$ Current-Reuse gm-Boosted CG LNA for Ultra wideband in $130 \mathrm{~nm}$ CMOS", IEEE Transactions on VLSI Systems, 2011.

[15] Behzad Razavi, "Design of Analog CMOS Integrated Circuits", McGraw Hill Pulications, Chapter 3 \& 6, 2001.

[16] S. Ngow and A. Thanachayanont. "A Low Voltage Wide Dynamic Range CMOS Floating Active Inductor". Proceedings of International Conference on Convergent Technologies for Asia-Pacific Region, Vol. 4, pp 1640-1643, October 2003.

[17] Fei Yuan, "CMOS Active Inductors and Transformers - Principle, Implementation, and Applications", Springer, Chapter-2, 2008.

[18] Robert Caverly, "CMOS RFIC Design Principles", Artech House Publications, Chapter - 4, 2007. 